\title{
Anatomical Study on the Celiac Artery in the Domestic Goose (Anser anser domesticus) with Special Reference to the Arterial Supply of the Stomach
}

\author{
Ragab, S.A., Farag, F.M.M., Tolba, A.R., Saleh, A.A. and El- \\ Karmoty, A.F. \\ Anatomy Department Faculty of Veterinary Medicine Cairo University
}

\section{Abstract}

The aim of this study was to investigate the course and distribution of the celiac artery in the domestic geese and also a trial to extend our knowledge on the geese which had received but little attention in the field of veterinary comparative anatomy .The present work was carried out on twenty apparently healthy domestic geese of different ages and sexes.The birds were anaesthetized by IM injection of $0.5 \mathrm{cc}$ of $2 \%$ xylazine $\mathrm{HCL}(3 \mathrm{mg} / \mathrm{kg})$. Colored gum milk latex $(60 \%)$ was then injected through the descending aorta. The specimens then after, were subjected to fine dissection to demonstrate the origin, course and distribution of the celiac artery.

The celiac artery gave off the esophageal artery, dorsal proventricular artery then bifurcated into left and right branches. The former branch gave off; Rr .succi, R. pyloricus, A. proventricularis ventralis and $A$. gastrica ventralis then continued as $A$. gastrica sinistra. The right branch detached the; Aa. lienales, A. hepatica dextra, A. ileocecalis, A. gastroduodenalis, A. pancreatico-duodenalis and $A$. gastrica dextra.

The glandular stomach (Proventriculus) received its main arterial supply from the dorsal and ventral proventricular arteries. The muscular stomach (ventriculus or gizzard) was supplied by four main vessels; the left, right, ventral and dorsal gastric arteries.

The obtained results were photographed, described and discussed with their corresponding features of other authors who performed earlier studies in other avis breeds. The nomenclature used was adopted 
according to the Nomina Anatomica Avium (1993).

Keywords: Anatomy, Celiac artery, stomach, Domestic goose.

\section{Introduction}

Geese are waterfowl belonging to the tribe Anserini of the family Anatidae. This tribe comprises the genera Anser (grey geese), Branta (black geese) and Chen (the white geese).On reviewing the available literature little could be found on the celiac artery in the goose. Malinovský and Visnanská (1975) and Aslan and Takci (1998) performed similar study in the domestic goose.

Proventriculotomy is commonly indicated for the removal of foreign objects, newspaper or other fibers which are not retrievable with the rigid or flexible endoscopes and may lead to proventricular impaction (Mc Cluggage, 1992; Van Sant, 2001). The aim of this study is therefore to give more knowledge on the anatomy of the celiac artery with special references to the arterial supply of the stomach which may be helpful for avian surgeons.

\section{Material and Methods}

Twenty adult domestic geese (Anser anser domesticus), 12 males, 8 females were used in the study. Before exsanguinations, the geese were anaesthetized by IM injection of 0.5 cc of $2 \%$ xylazine $\mathrm{HCL}(3$ $\mathrm{mg} / \mathrm{kg}$ ), followed by the injection of heparin (Cal Heparin, 5000 I.U.) in the wing vein to prevent blood clotting.

Each specimen was then exsanguinated through the common carotid arteries and left to bled for five minute The breast muscles and sternum were carefully removed to expose the heart. Latex neoprene $60 \%$ colored with red Rottring ink was injected into the descending aorta using a Nelaton catheter of size $8 \mathrm{~F}$ to $10 \mathrm{~F}$ (Ma Medical company). The specimens were then kept at $+4^{\circ} \mathrm{C}$ for 24 to ensure the freezing of latex and then preserved in $10 \%$ formalin $4 \%$ phenol and $1 \%$ glycerin three days before dissection.

The specimens were photographed using Olympus digital camera SP600UZ 12 mega pixel. The nomenclature used in this study was that given by the Nomina Anatomica Avium (Baumel et al., 1993).

\section{Results}

\section{A. celiaca}

The celiac artery (Figs. 1, 3, 4 and $6 / 2$ ) originated from the right face of the descending aorta on a level with the last $5^{\text {th }}$ to $6^{\text {th }}$ vertebral rib at the 
junction of the esophagus with the proventriculus. It extended caudoventrally between the right lobe of the liver and proventriculus for about $1.3 \mathrm{~cm}$ and terminated on level with the cranial aspect of the spleen into two main branches left and right. Just close to its origin, the celiac artery gave off the esophageal and dorsal proventricular arteries.

\section{A. esophagealis}

The esophageal artery (Fig. 1/3) was represented by a slender vessel arising from the celiac artery close to its origin from the aorta (12 specimens) or from the dorsal proventricular artery (8 specimens). It proceeded cranially on the dorsal aspect of the thoracic esophagus, giving fine twigs to that portion and finally anastomosed with the esophageal branch of the esophagotracheobronchial artery.

\section{A. proventricularis dorsalis}

The dorsal proventricular artery (Figs. 1, 3, 4 and 6/4) was given off from the left wall of the celiac artery, close to its origin from the aorta descendens. It extended caudally along the dorsal aspect of the proventriculus and terminated at the isthmus of the stomach. While it was coursing on theproventriculus, it released 2-3 esophageal branches that ramified at the junction of the esophagus with proventriculs and 8 - 10 collateral branches to the dor- sal wall of the proventriculus, and to the isthmusgastris.

\section{R. sinister arteriae celiacae}

The left branch of the celiac artery (Figs. 1, 3 and 6/5) was directed to the left, ventral to the Isthmus gastris in the cranial groove of the ventriculus then curved caudally on the left surface of the ventriculus as the left gastric artery. During its course, the left branch of the celiac artery gave off; Rr. succi, R.pyloricus, A.proventricularis ventralis and A.gastrica ventralis.

\section{Rr. succi}

The branches of the saccus cranialis (Figs. 1 and 3/6) were represented by 1-2 branches that arose from the left branch of the celiac artery just below the left aspect of the isthmus gastris. It proceeded caudally for a short distance and ramified in the craniodorsal tenuis muscle as well as the Bulbus pyloricus, anastomosing with the gastroduodenal artery.

\section{R. pyloricus}

The pyloric branch (Figs. 2 and 4/12) arose from the left branch of the celiac artery opposite to the origin of the left hepatic arteries. In eight specimens it was given from one of the latter vessels before entering the left hepatic lobe. It rewinded to left surface of the ventric- 
ulus and ramified in the Bulbus pyloricus as well as the commencement of the duodenum descendens and anastomosed with the gastroduodenal artery.

\section{A. Proventricularis ventralis}

The ventral proventricular artery (Fig. 2/7) was arisen from the dorsal aspect of the left branch of the celiac artery after approximately $2 \mathrm{~cm}$ from the origin of the latter vessel. It proceeded between the left lobe of the liver and the ventriculus, detached 1-2 branches to the gastric isthmus then continued cranially along the ventral aspect of the proventriculus supplying this aspect with 3-5 collateral branches and then terminated into 2-3 fine twigs that supplied the ventral aspect of the thoracic esophagus.

\section{A. gastrica ventralis:}

The ventral gastric artery (Fig 2/13) originated from the ventral aspect of the left branch of the celiac artery, about $1 \mathrm{~cm}$ below the origin of the ventral proventricular artery. It gave off the left hepatic arteries, 1-2 branches to the cranioventral crassus muscle. It then extended caudally along the ventral margin of the ventriculus giving collateral rami to that portion and anastomosed with both the right ventral andleft ventral gastric arteries in the vicinity of the caudal sulcus of the ventriculus.

J. Vet. Anat.

\section{Aa. hepaticae sinistrae}

The left hepatic arteries (Fig. 2/11) were represented by two large vessels and 1-2 relatively smaller ones that originated from the cranial aspect of the ventral gastric artery and extended cranioventrally for a short distance before entering the left lobe of the liver.

\section{A. gasrtica sinistra}

The left gastric artery (Fig. 2/8) represented the direct continuation of the left branch of the celiac artery after giving off the ventral gastric artery. It extended on the sulcus cranialis to the left surface ofthe ventriculus and divided nearly at the level of the central tendon into two branches, the dorsal left and ventral left gastric arteries. Along its course the left gastric artery detached collateral branches to the craniodorsal tenuis and cranioventral crassus muscles. The dorsal left gastric artery (Figs. 2 and 6/9) ascended in a caudodorsal course towards the dorsal aspect of the ventriculus where it anastomosed with the dorsal gastric artery as well as the corresponding right dorsal gastric artery. Along its course it detached collateral branches supplying the craniodorsal tenuis, caudodorsal crassus muscles. The ventral left gastric artery (Figs. 2 and 6/10) proceeded in a caudal direction to reach the caudal sulcus of the ventriculus where it anastomosed with 
the corresponding branch of the right ventral gastric artery and the ventral gastric artery. It gave off three main rami; dorsal ventral and caudal that supplied the centrum tendeum, caudoventraltenuis, caudoventralcrassus muscles respectively.

\section{R. dexter arteriae celiacae}

The right branch of the celiac artery (Fig. 1, 3, 4, 5 and 6/14) was the larger of the two branches into which the celiac artery terminated and from points of size and direction it represented the direct continuation of the parent vessel. It proceeded in a caudoventral direction between the spleen and right lobe of the liver and on reaching the right aspect of the pylorus it continued as the right gastric artery. Along its course the right branch of the celiac artery gave off; splenic, right hepatic, ileocecal, gastroduodenal and pancreaticoduodenal arteries.

\section{Aa. lienales (Aa.splenicae)}

The splenic arteries (Fig. 1, 3, 4 and 6/15) were represented by two vessels entering the splenic hilus. The cranial one was larger and arose from the right branch of the celiac artery close to the bifurcation of the latter vessel. The caudal one was much smaller and originated about $0.5 \mathrm{~cm}$ caudalto the cranial one.

\section{A. hepatica dextra}

The right hepatic artery (Fig. 3, 4 and $6 / 16$ ) constituted a single vessel arising from the right branch of the celiac artery in between the two splenic arteries. It gave off the A.vesicae biliaris and A. duodenojejunalis and terminated by dispersing into the right lobe of the liver.

\section{A. vesicae biliaris (A. vesicae felleae)}

The artery of the gall bladder (Fig. 4/17) was in the form of a short vessel arising from either the right hepatic artery (12 specimens) or duodenojejunal artery (4 specimens ) or represented by two small rami (4 specimens), one from each of the latter vessels. It dispersed fine twigs that ramified in the wall of the gall bladder.

\section{A. duodenojejunalis}

The duodenojejunal artery (Fig. 4/18) was arisen from of the right hepatic artery about $2-3 \mathrm{~mm}$ after its origin. It was dispersed to the duodenojejunal flexure by dividing into two branches; the duodenal branch (Fig. 4/19) ramified in the distal portion of the duodenum ascendens and anastomosed with the pancreaticoduodenal artery, and jejunal branch (Fig. 4/20) that arborized in the duodenojejunal flexure and initial portion of the jejunum and it ended by anastomosing with the similar branch of the cranial mesenteric artery on this level. 


\section{A. ileocecalis}

The ileocecal artery (Fig. 1, 3, 4, 5 and 6/21) was represented by a single vessel arising from the right branch of the celiac artery near its termination. In four specimens it was given off from the pancreaticoduodenal artery. The ileocecal artery proceeded into the ansa supraduodenalis for short distance and divided into two branches; cranial and caudal. The cranial branch (Figs. 1, 3, 4, 5 and 6/22) extended along the cranial half of the left cecum to its apex, giving off 8-10 cecal branches (Fig. 5/22B) to that portion of the cecum and 6-8 ileal branches (Fig. 5/22A) that extended in the mesentery connecting the left ceum with the ileum and ramified to the adjacent portion of the ileum and anastomosed with the ileal arteries of the cranial mesenteric artery. The caudal branch (Figs. 1, 3, 4, 5 and 6/23) was smaller than the cranial one and ramified in the next quarter of the left cecum and adjoin portion of the ileum and anastomosed with the corresponding branches of the ileocecal artery arising from the cranial mesenteric artery.

\section{A. gastroduodenalis}

The gastroduodenal artery (Fig. 1, 3,4 and 5/24) was a short vessel, originating from the leftwall of the right branch of the celiac artery near its termination as the right gastric artery. In six specimens it arose from the latter vessel. It was distributed to the craniodorsal tenuis muscle, the pylorus and the initial portion of the duodenum descendens and ends by ananastomosing with the Rr.succi and R.pyloricus of the left branch of celiac artery.

\section{A. pancreaticoduodenalis}

The pancreaticoduodenal artery (Fig. 1, 3, 4, 5 and 6/25) was observed to originate from the right branch of the celiac artery near its termination opposite to the origin of the gastroduoudenal artery. In eight of the examined specimens it was observed to arise from the ventral branch of the right gastric artery. It runs to the Ansa duodeni in the mesentery connecting the ascending and descending parts of the duodenum to the flexura duodeni. Along its course, it gave off $\mathbf{R r}$. pancreatici (Fig. 6/26) and Rr. duodenales (Figs. 1, 3, 4, 5 and 6/27). These rami were arisen at different levels and dispersed to the corresponding organs.

\section{A. gastricadextra}

The right gastric artery (Fig. 1, 3, 4 and $5 / 28$ ) was represented by a short vessel about $0.5 \mathrm{~cm}$. It was considered as continuation of the right branchof the celiac artery at the level of the ascending part ofduodenum. It was seen to divide just after its origin into two branch- 
es; the right dorsal and right ventral gastric arteries. However in six of the specimens the short stem representing the right gastric artery was not formed and the latter two arteries were originated directly by the bifurcation of the right branch of the celiac artery. The dorsal right gastric artery (Fig. 1, 3, 4, 5 and $6 / 29$ ) extended caudodorsally, contributed 2-4 branches to the craniodorsal tenuis muscle, centrum tendineum as well as the caudodorsal crassus muscle. The ventral right gastric artery (Fig. 1, 3, 4, 5 and $6 / 30$ ) proceeded in a caudalward direction to reach the caudal sulcus. Along its course it gave off 3-5 collateral ramis to the centrum tendineum, cranioventral crassus and caudoventral tenuis muscles. On reaching the latter sulcus itanastomosed with the corresponding branch of the left gastric artery then continued craniodorsally along the caudal sac as the dorsal gastric artery (Fig. 6/31) that supplied the caudodorsal crassus muscle and anastomosed with the dorsal branches of both left and right gastric arteries.

\section{Discussion}

In the goose as recorded in other domestic fowl (Baumel, 1975; Franz and Salomon, 1993; Silva et al., 1997; Dursun 2002; Kurtul and Haziroglu, 2004; Kuru, 2010), roos- ter, duck and pigeon (Kurtul 2002; Kurtul and Haziroglu, 2002), domestic duck (Malinovsky et al., 1973), the celiac artery was arising from the right face of the descending aorta on a level with the last $5^{\text {th }}$ to $6^{\text {th }}$ vertebral rib at the junction of the esophagus with the proventriculus. It gave off the esophageal artery and dorsal proventricular artery then divided into left and right branches.Silva et al. (1997) added that the celiac artery sent a vessel to the pericardium called the cardiac artery which was not observed in this study. Aycan and Duzler (2000) reported that the celiac artery in the eagle owl did not bifurcate and gave off nine branches.

The present study revealed the origin of the esophageal artery from either the celiac artery or the dorsal proventricular artery, the same as recorded by haligur and duzler (2010) in the red falcon. Malinovsky and Visnansk (1975) in the domestic goose and the Nomina Anatomica Avium (Baumel et al., 1993) in the family Falconidae described the esophageal artery as stemming from the aorta. In the present study, the esophageal artery was referred to as the $A$. esophagea recurrens as described also by Nishida et al. (1969) in fowl.

The current investigation recorded that the dorsal proventricular artery 
was given off from the celiac artery, extended caudally along the dorsal aspect of the proventriculus and terminated at the isthmus of the stomach. Nishida et al. (1969) designated the corresponding vessel in the fowl as the right glandular gastric artery .Baumel (1975), Levinsohn et al. (1984) and Kuru (2010) in the domestic fowl stated that the dorsal proventricular artery continued as the dorsal gastric artery on the ventriculus.Statement which could not be ascertained in the goose in which the latter vessel was formed by the continuation of the ventral right gastric artery. On the other hand the dorsal gastric artery in the fowl was described as a continuity of the pancreaticoduodenal artery (Silva et al., 1997), or the right branch of the celiac artery (Kuru, 2010).

In accordance with Baumel (1975), Baumel et al. (1993), Franz and SaIomon (1993), Malinovsky and Novotna (1977) and Kuru (2010) in the domestic fowl the left branch of the celiac artery gave off the ventral proventricular and ventral gastric arteries and terminated as the left gastric artery. Moreover, in goose the left branch gave off Rr.succi to the craniodorsal sac as recorded by Baumel et al. (1993) as well as a pyloric branchas mentioned by Nishida et al. (1969) to the junction

between the stomach and duodenum.

In the present study as well as in the domestic fowl (Kuru, 2010) the ventral gastric artery was originated from the left branch of the celiac artery, and extended caudally along the ventral aspect of the ventriculus. Haligur, Duzler (2010) in red falcon recorded that the ventral gastric artery was represented by 2-3 vessels. Nickel et al. (1977) in the fowl mentioned that the ventral gastric artery was continued as the A. gastropancreaticoduodenalis from which arose a branch going to the muscular stomach and rami ileocaecales to the middle section of the caeca and the ileum then it continued as the A. pancreaticoduodenalis.

In the goose, the left hepatic arteries were represented by two large vessels and 1-2 relatively smaller ones that originated from the ventral gastric artery. However, a single left hepatic artery from the same origin was recorded in the domestic goose (Malinovsky and Visnanska, 1975), domestic fowl (Kuru, 1996; Dursun, 2002; and Kuru, 2010) and pigeon (Kurtul, 2002). In a Eurasian eagle owl, the same vessel has been reported to stem directly from the celiac artery (Aycan and Duzler, 2000). The present study as well as those made by Kuru (2010) in the do- 
mestic fowl revealed that the left gastric artery represented the direct continuation of the left branch of the celiac artery and was divided into two branches, the dorsal left and ventral left gastric arteries. Haligur, Duzler (2010) in red falcon stated that it had a fan-like distribution to the left surface of the gaster. Mahdy (2009) in the ostrich added that the left gastric artery gave off 5-7 twigs dorsal and 4-6 ventral collateral twigs before its bifurcation into dorsal and ventral terminal branches.

In the goose the splenic arteries were represented by two branches the same as recorded in the chicken by Kuru (1996) and (Kuru, 2010) and in the Eurasian eagle owl byAycan and Duzler (2000). The number of splenic arteries in chickenshas been reported to be 2-8 in domestic fowl by Malinovsky and Novotna (1977), 2-6 in the duck by Pinto et al. (1998), 3-6 in the pigeon and 4-6 in the roosterby Kurtul (2002). The origin of the splenic arteries from the right branch of the celiac artery was also recorded by Kuru (2010) in the fowl. Baumel et al.( 1993) in the chicken, Aycan and Duzler (2000) in the Eurasian eagle owl and Haligur, Duzler (2010) in red falcon recorded the origin of the splenic arteries directly from the celiac artery. Furthermore, in a study carried out in three different chicken breeds (Malinovsky and Novotna, 1977) the spleen was vascularised by one or more branchesarising from the right hepatic artery, left branch of celiac artery, or even from the superior proventricularartery. In the domestic goose the right hepatic artery erupted from the right branch of the celiac artery. The same as recorded in the fowl (Baumel et al., 1993; Dursun, 2002; Kuru, 2010) and goose (Aslan and Takci, 1998). In contrast to this, Haligur and Duzler, (2010) in the red falcon mentioned that the right hepatic artery arose from the left branch of the celiac artery. Kaupp (1918) mentioned that the A. hepatica dextra was a branch from the celiac artery. The right hepatic artery gave off the vesical artery to the gall bladder (Baumel, 1975; Franz and Salomon, 1993; Malinovsky and Novotna, 1977). On the other hand the artery of the gall bladder was demonstrated to emanate from the left branch of the celiac artery in the red falcons (Haligur and Duzler, 2010). Moreover the right hepatic artery was determined to give off the duodenojejunal artery and jejunal artery in the fowl (Baumel, 1975; Franz and Salomon, 1993; Silva et al., 1997). Similar findings were recorded in the goose but the latter artery could not be ascertained in any of the examined specimens. The duodenjejunal artery was ob- 
served to divide into a duodenal branch and a jejunal branch. The duodenojejunal was described as the continuation ofthe right branch of the celiac artery in the chicken (Baumel, 1975; Franz and Salomon, 1993; Malinovsky and Novotna, 1977).

The present study recorded single ileocecal artery arising from the right branch of the celiac artery near its termination and in four specimens it was given off from thepancreaticoduodenal artery. In this connection, in the fowl, Baumel (1975), Malinovsky and Novotna (1977) and Nickel et al. (1977) recorded 1-5 ileocecal arteries arising from the duodenojejunal artery. Silva et al. (1997) and Kuru (2010) in the domestic fowl reported 1- 4 and two ileocecal arteries respectively arising from the pancreaticoduodenal artery.

The present study revealed that the duodenojejunal artery was arisen from of the right hepatic arteryand dispersed to the duodenojejunal flexure by dividing into two branches, duodenal branch and jejunal branch. On the other hand in the fowl Baumel (1975), Franz and SaIomon (1993) and Malinovsky and Novotna (1977) mentioned that the duodenojejunal.artery was the continuation ofthe right branch of the celiac artery between the ascending and descending part of the duodenum

In the goose of this study, the gastroduodenal artery originated from either the right branch of the celiac artery or the right gastric artery. It was distributed to craniodorsal tennis muscle, thepylorus and the initial portion of the duodenum descendens. Similar results were recorded in the domestic fowl (Kuru, 2010) and red falcon (Haligur and Duzler, 2010). On the other hand Baumel et al (1993) reported the corresponding vessel in the chicken as arising from the left branch of the celiac artery.

The current investigation revealed that the pancreaticoduodenal artery arose from the right branch of the celiac artery or from the ventral branch of the right gastric artery. In fowl (Kuru, 2010) mentioned that the pancreaticoduodenal artery represented the continuation of the right branch of the celiac artery while Mahdy (2009) in the ostrich revealed the bifurcation of the latter vessel into the right gastric and pancreaticoduodenal arteries. On the other hand Nickel et al. (1977) recorded that the pancreaticoduodenal artery was formed by the continuity of the gastropancreaticoduodenal artery. In the goose as in the fowl (Kuru, 2010) the pancreati- 
coduodenal arteries run in the mesentery connecting the ascending and descending parts of the duodenum to the flexura duodeni giving off Rr.pancreatici and Rr. duodenales. In this respect in the red falcon (Haligur and duzler, 2010) this artery was divided into two branches. One of the bifurcated branches extended along the flexura duodeni and pars descendens duodeni while the other branch was ascertained to run along the pars ascendens duodeni.

According to the present study, the right gastric artery represented the continuation of the right branch of the celiac artery and was divided into two branches the dorsal right and ventral right gastric arteries. However the latter two rami could be matched favorably with the right superior and right inferior gastric arteries arising from the right branchof the celiac artery without forming stem right gastric artery as recorded in the N.A.A. (Baumel et al., 1993) and in the red falcon (Haligur and duzler, 2010). Similar pattern was observed in six specimens in the present study.

The present data agree with the recommendation made by McCluggage (1992) that the left lateral coeliotomy is the most useful approach access to the proventriculus and ventriculus. The optimum inci- sion site is the left aspect of the Isthmus gastris and extended cranially on the left wall of the proventriculus to avoid injury of the dorsally and ventrally oriented dorsal and ventral proventricular arteries respectively.

\section{References}

Aslan K. and Takci, I. (1998): The arterial vascularitsaition of the organs (stomach, intestinum, splen, kidneys, testes and ovarium) in the abdominal region of the geese obtained from Kars surrounding. Kafkas Universitesi Veteriner Fakultesi Dergisi, 4, 49-53.

Aycan K. and Duzler A (2000): The anatomy of celiac artery in the eagle owl (Bubo bubo). Ankara Universitesi Veteriner Fakultesi Dergisi, 47, 319-323.

Baumel, J.J. (1975): Aves Heart and Blood Vessels. In, Sisson and Grossman's the Anatomy of the Domestic Animals. Getty R (Eds.), Vol II, 5 th ed. Saunders Company, Philadelphia, 1990-1991.

Baumel, J.J., King, S.A., Breasile, J.E., Evans, H.E. and Berge, J.C.V. (1993): Nomina Anatomica Avium.Published by the Nuttall Ornithological Club. No: 23, Cambridge, Massachusets. 
Dursun, N. (2002): Anatomy of Domestic Birds. Medisan Publishing, Ankara. 140-141

Franz, V. and Salomon, V. (1993): Lehrbuch der Geflügelanatomie. Gusav Fischer Verlag, Jena, Suttgart.

Haligur, A., Duzler, A. (2010): Course and branch of the celiac artery in the red falcon (Buteorufinus) Veterinarni Medicina, 55, 2010 (2): 79-86

Kaupp, B. F. (1918): The anatomy of the domestic fowl. London, W. B. Saunders Company.

Kurtul, I. (2002): Comparative macroanatomical investigations on the pattern and branches of the aorta descendens among the rooster, drake, and pigeon (in Turkish). [Ph.D. Thesis]. Faculty of Veterinary Medicine, Ankara University.

Kurtul, I., Haziroglu. R.M. (2002): Comparative macroanatomical investigations on the pattern and branches of the descending aorta among the rooster, drake, and pigeon (in Turkish). Journal of the Faculty of Veterinary Medicine, Ankara University, 51, 1-6.

Kuru, N. (1996): Macroanatomical investigation of course and branch- ing of aorta in domestic chick and New Zealand rabbit (in Turkish). [Ph.D.Thesis] Faculty of Biology Selcuk University.

Kuru, N. (2010): Macroanatomic investigations on the course and distribution of the celiac artery in domestic fowl (Gallus gallus domesticus).Scientific Research and Essays Vol. 5(23), pp. 3585-3591, 18.

Levinsohn, E. M., Packard, D. S., West, E.M., Hootnick, D.R. (1984): Arterial anatomy of chicken embryo and hatchling. Am. J. Anat., 169: 377-405.

Mahdy, E.A.A. (2009): some anatomical studies on the stomach of ostrich (Struthio camelus).M.V.Sc. Thesis, Fac. Vet. Med. Zagazig Univ.

Malinovský L, Novotná M. (1977): Branching of the coeliac artery in some domestic birds. iii. A comparison of the pattern of the coeliac artery in three breeds of the domestic fowl (Gallus gallus domestica).Anat. Anz. 1977; 141(2):137-46.

Malinovský L, Visnanská M. (1975): Branching of the coeliac artery in some domestic birds II. The domestic goose. Folia Morphol. (Praha).1975; 23(2):128-35. 
McCluggage, D. (1992): Proventriculotomy: A study of selected cases, in: Proceedings of the Annual Conference Association of Avian Vets. Lake Worth Florida 195-200.

Nickel, R., Schummer, A. and Seiferle, E. (1977): Anatomy of the Domestic Birds. Verlag Paul Parey, Berlin.

Nishida, T., Paik, Y.K. and Yasuda M (1969): Blood vascular supply of the glandular stomach (Ventriculusglandularis) and the muscular stomach (Ventriculus muscularis). Jpn. J. Vet. Sci., 31: 51-70.
Pinto, M.R.A., Riberio, A.A.C.M. and Souza, W.M. (1998): Os arranjos configurados pela arteria celiaca no patodomestico (Carinamoshata). Braz. J. Vet. Res. Anim. Sci., 35: 103-106

Silva,F.O., Severino, R.S., Santos, A.L.Q., Drummond, S.S., Bombonato, P.P., Santana, M.I.S., Lopes, D., Marçal, A.V. (1997): Origin and distribution of the arteria celiaca in birds (Gallus gallus domesticus-Ross linage). Revista da FZVA,4 (1): 64-76. 
Chart (1): Showing summary for the main arteries devoted to vascularize the stomach of the domestic goose.

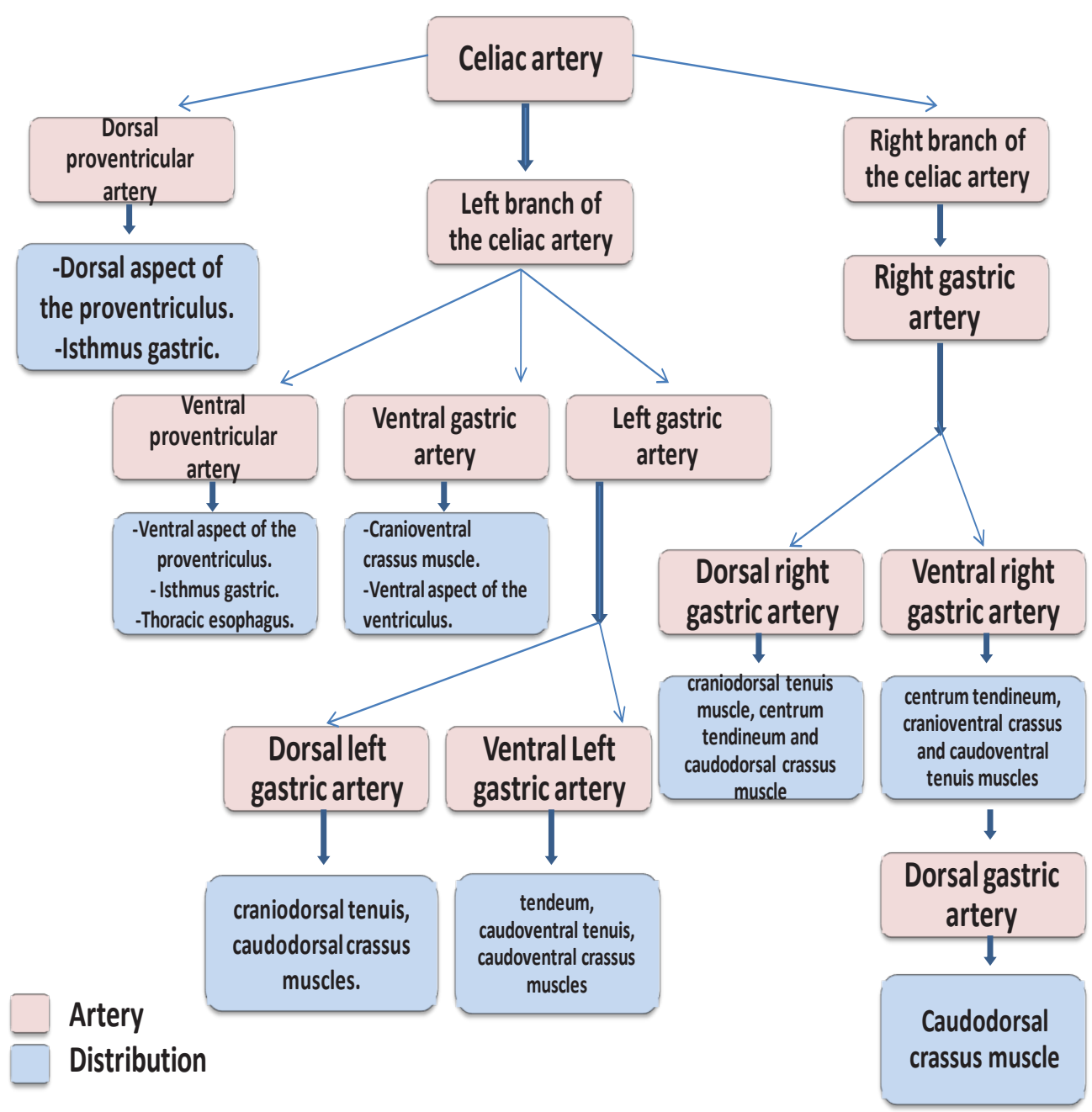




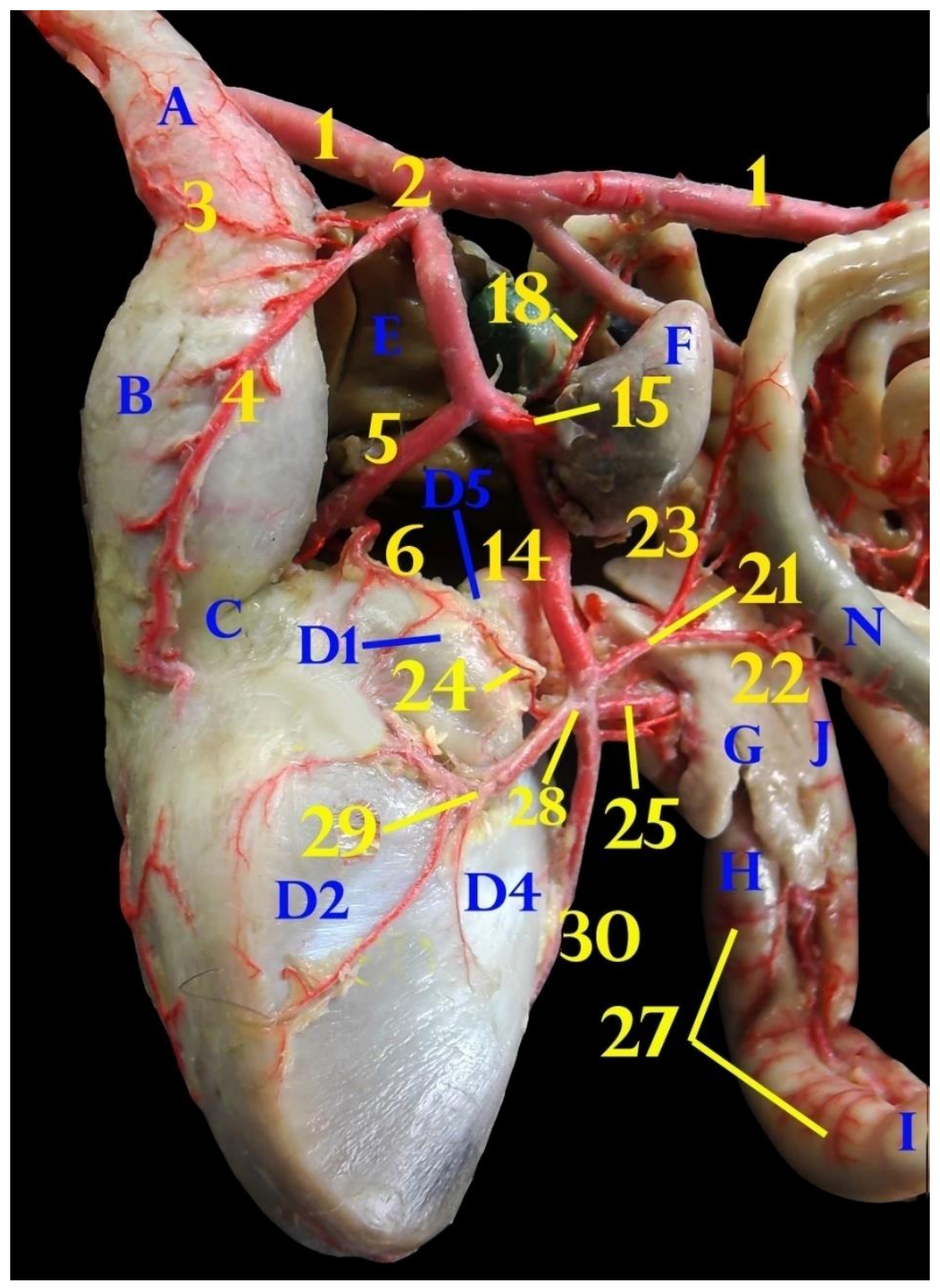

Fig (1): A photograph showing the branches of the celiac artery in goose (Dorsal view) 


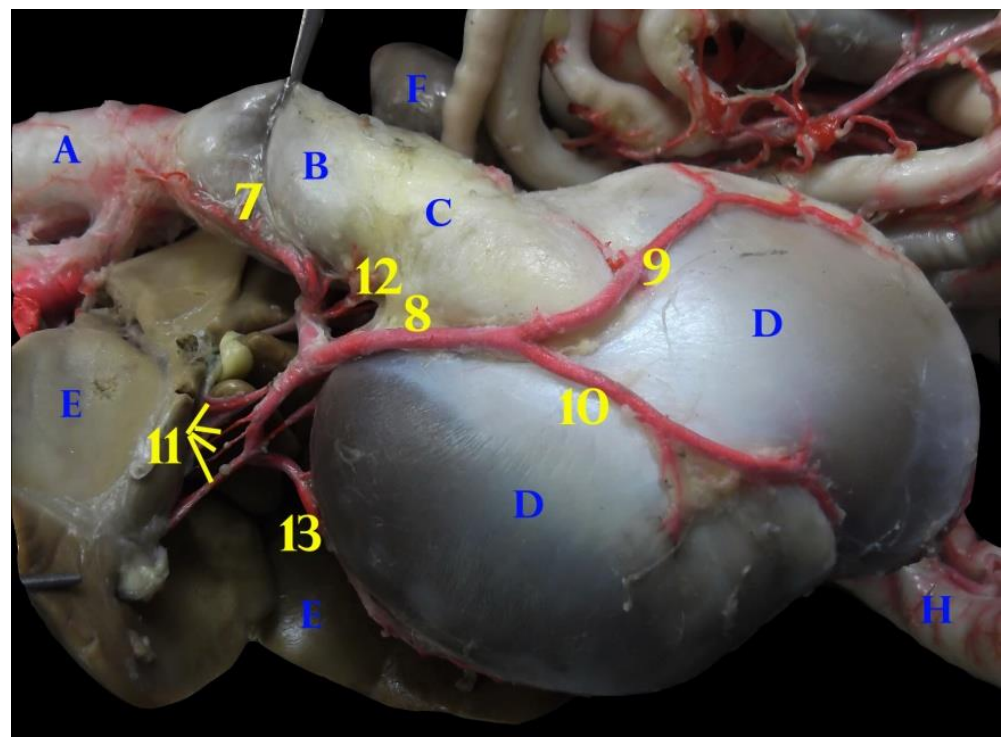

Fig (2): A photograph showing the branches of the celiac artery in goose (Left view)

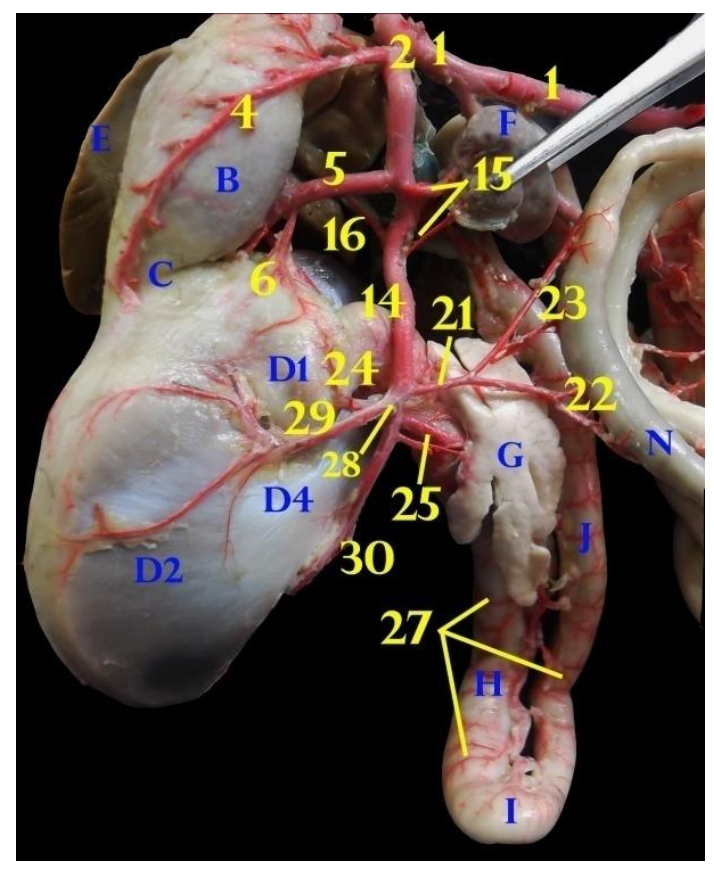

Fig (3): A photograph showing the branches of the celiac artery in goose (Right view) 


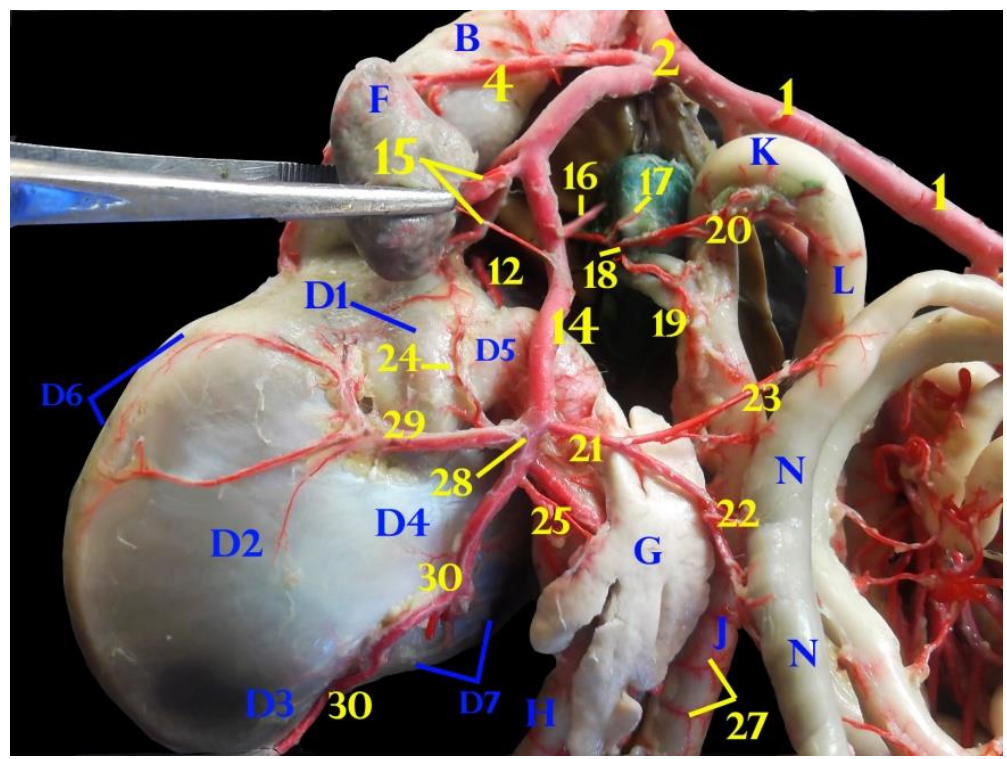

Fig (4): A photograph showing the branches of the celiac artery in goose (Right view)

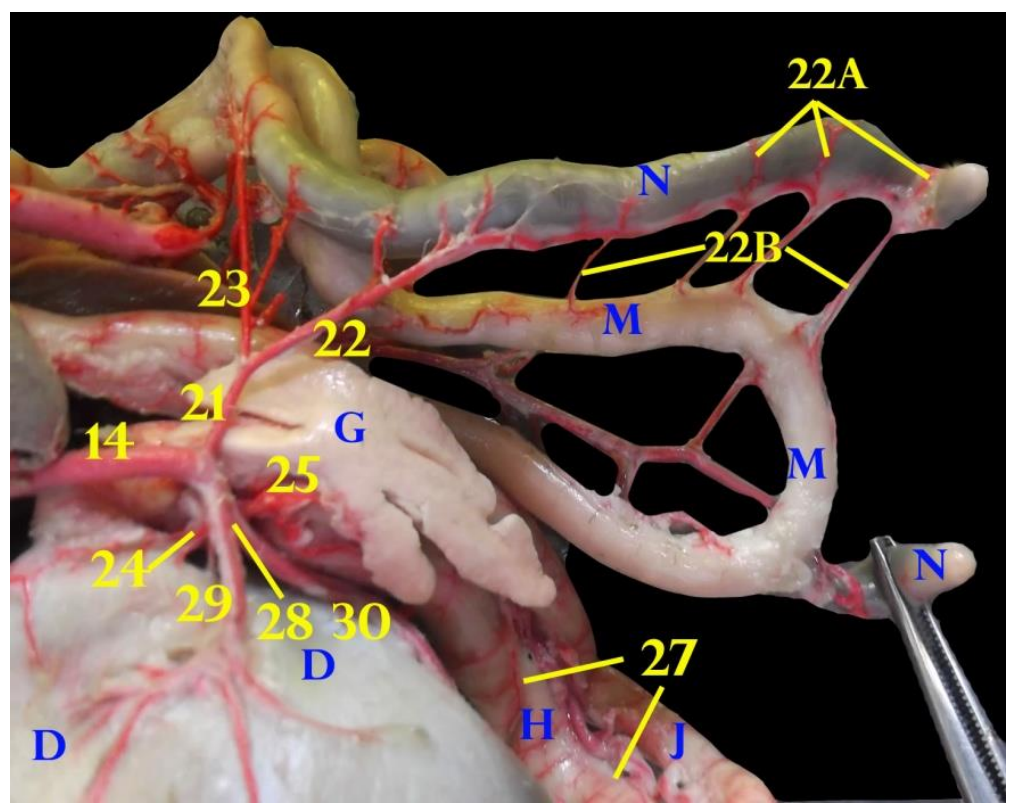

Fig (5): A photograph showing the branches of the celiac artery in goose (Dorsal view) 


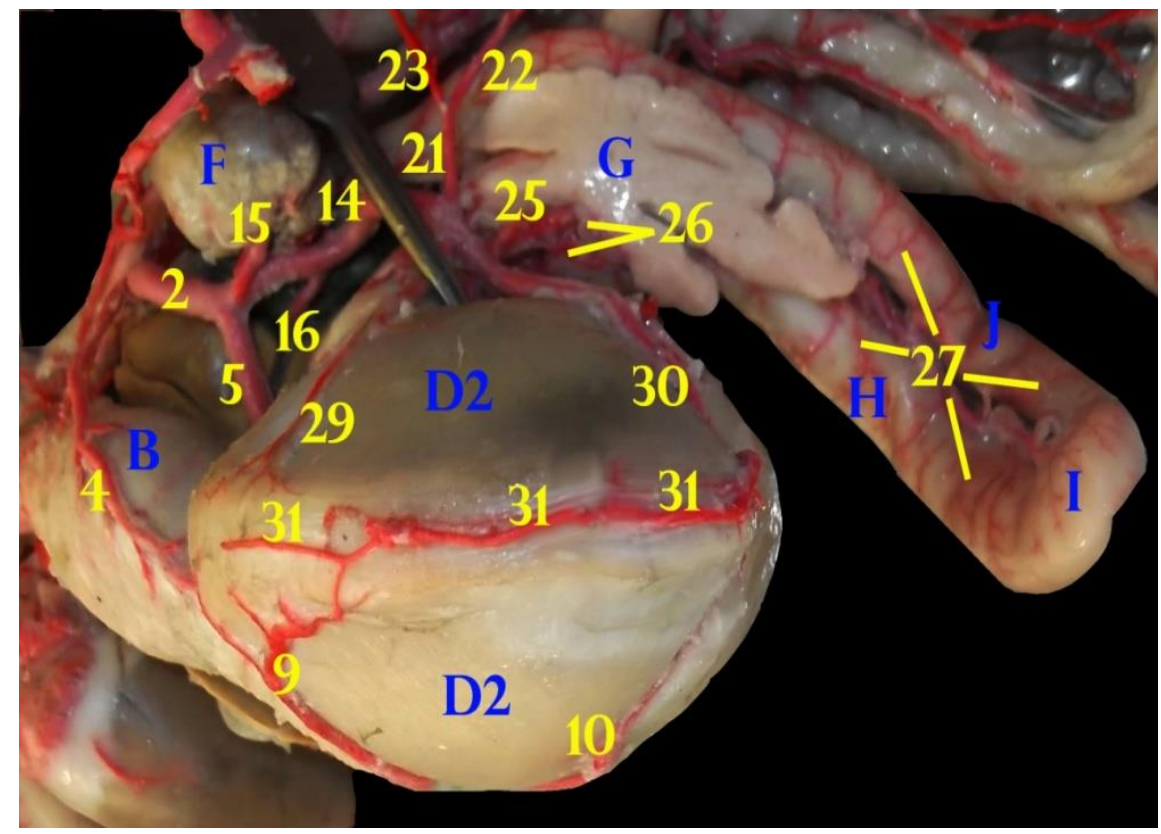

Fig (6): A photograph showing the branches of the celiac artery in goose (Right view)

\section{Legend for the figures from 1-6}

1 Aorta descenedens, 2A.celiaca, 3 A.esophagealis, 4 A. proventricularis dorsalis, $\bullet \mathrm{R}$. sinister arteriae celiacae, $6 \mathrm{R}$. sacci of 5,7 A. proventricularis ventralis, 8 A. gastrica sinistra, 9 A. gastrica sinistra dorsalis, $10 \mathrm{~A}$. gastrica sinistra ventralis, $11 \mathrm{~A}$. hepatica sinistra, $12 \mathrm{R}$. pylorica of $5,13 \mathrm{~A}$. gastrica ventralis,14R. dexter arteriae celiacae, $15 \mathrm{Aa}$. lienales, $16 \mathrm{~A}$. hepatica dextra, $17 \mathrm{~A}$. vesicea biliarisfelleae, $18 \mathrm{~A}$. duodenojejunalis, 19 $\mathrm{R}$. duodenalis of 18, $20 \mathrm{R}$.jejunalis of 18, 21A.ileocecalis, $22 \mathrm{R}$. cranialis of $21,22 \mathrm{~A} \mathrm{Rr}$. Cecales, 22B. Rr. iliales, 23 R.caudalis of 21,24 A. gastroduodenalis, 25 A. pancreaticoduodenalis, $26 \mathrm{Rr}$. Pancreatici of 25, $27 \mathrm{Rr}$. duodenales of 25, 28 A. gastrica dextra, 29 A. gastrica dextra dorsalis, 30 A. gastrica dextra ventralis, 31 A. gastrica dorsalis.

A Esophagus, B Proventriculus gastris, C Isthmus gastris, D Ventriculus gastris (Gizzard), D1 M.tenuis craniodorsalis, D2 Corpus ventriculi, D3 M.tenuis caudoventralis, D4 Centrum tendineum, D5 Pars pylorica, D6 M.crassus caudodorsalis, D7 M.crassus cranioventralis, E Hepar, F Lien, G Pancreas, H Pars descendens duodeni, I Flexura duodeni, J Pars ascendens duodeni, K Flexura duodenojejunalis, L Jejunum, M lleum, N Cecum. 